\title{
An Evaluation of the Effectiveness of a Nurse-Run Clinic for Women at Increased Risk for Breast Cancer on Anxiety, Depression, and Cancer Worry
}

\author{
Lisa Muto \\ West Virginia University
}

Follow this and additional works at: https://researchrepository.wvu.edu/etd

\begin{abstract}
Recommended Citation
Muto, Lisa, "An Evaluation of the Effectiveness of a Nurse-Run Clinic for Women at Increased Risk for Breast Cancer on Anxiety, Depression, and Cancer Worry" (2011). Graduate Theses, Dissertations, and Problem Reports. 3079.
\end{abstract}

https://researchrepository.wvu.edu/etd/3079

This Dissertation is protected by copyright and/or related rights. It has been brought to you by the The Research Repository @ WVU with permission from the rights-holder(s). You are free to use this Dissertation in any way that is permitted by the copyright and related rights legislation that applies to your use. For other uses you must obtain permission from the rights-holder(s) directly, unless additional rights are indicated by a Creative Commons license in the record and/ or on the work itself. This Dissertation has been accepted for inclusion in WVU Graduate Theses, Dissertations, and Problem Reports collection by an authorized administrator of The Research Repository @ WVU.

For more information, please contact researchrepository@mail.wvu.edu. 
An Evaluation of the Effectiveness of a Nurse-Run Clinic for Women at Increased Risk for Breast Cancer on Anxiety, Depression, and Cancer Worry

\title{
Lisa Muto
}

Doctoral Research Project submitted to the School of Nursing at West Virginia University in partial fulfillment of the requirements for the degree of

Doctor of Nursing Practice

\author{
Susan McCrone, PhD, PMHCNS-BC, RN, Chair \\ Nan Leslie, PhD, RNC, CRNP \\ Shawn McKinney, MD, FACS \\ Department of Nursing
}

Morgantown, WV

2011

Keywords: high, risk, breast, cancer, clinic, anxiety, depression, and cancer worry 


\section{ABSTRACT \\ An Evaluation of the Effect of an Educational Intervention at a Nurse-Run Clinic for Women at Increased Risk for Breast Cancer on Anxiety, Depression, and Cancer Worry}

\section{Lisa Muto}

Many women have risk factors that can increase their risk for developing breast cancer. These women may benefit from recommendations based on their personal and family history. Women at increased risk may experience higher levels of anxiety, depression, or cancer worry than women who are at average or only slightly increased risk. By providing these women with an accurate risk assessment, these factors may be decreased. The purpose of this project was to evaluate the effect of a nurse-run clinic for women at increased risk for breast cancer on anxiety, depression, and cancer worry.

A pre-test/post-test longitudinal design was used with a convenience sample of women at increased risk for breast cancer. Participants completed a Modified Ways of Coping Scale, the State portion of the State Trait Anxiety Inventory, the Brief Zung Self Rating Depression Scale, and Lerman's Breast Cancer Worry Scale prior to their appointment. Two weeks after the appointment, participants were asked to complete the anxiety, depression and cancer worry tools again by mail. Demographic data was also collected.

The visits were tailored based on the coping questionnaire. Results were marginally significant for a decrease in anxiety. Results were non-significant for depression and cancer worry. Means for all variables decreased. Recommendations include continuing to assess anxiety, depression, and cancer worry at the high-risk clinic at ECCC. 


\section{Acknowledgements}

This project would not have been possible without the support of many people. I would like to take this time to thank each of you:

- To my committee members, Dr. Susan McCrone, Dr. Nan Leslie, and Dr. Shawn McKinney: I would like to express my deepest gratitude for your direction and support throughout this project. Without your knowledge and assistance this study would not have been successful. I wish to especially express my appreciation to my chair, Dr. McCrone, who was abundantly helpful and offered invaluable assistance, support and guidance.

- To my mother and stepfather, Lynn and Bill Walker, always proud supporters of all my educational endeavors.

- To my husband, Marc, thank you for your patience and encouragement, I could not have done this without your support.

- Finally, I wish to acknowledge my late father, Dennis Claypool, who was always my biggest cheerleader and the reason I chose to practice in oncology. 


\section{Table of Contents}

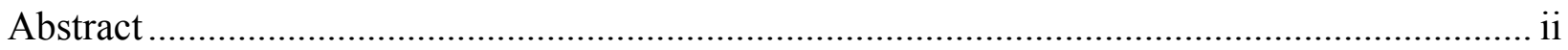

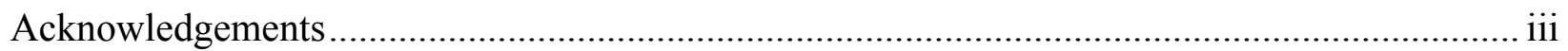

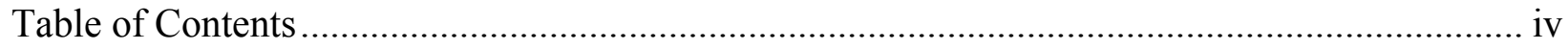

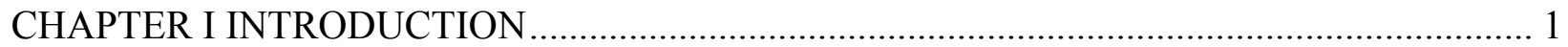

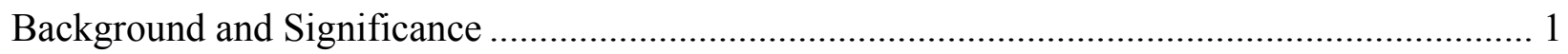

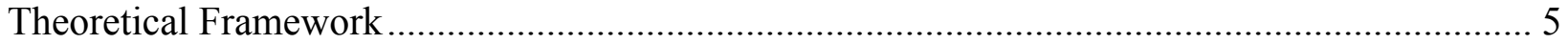

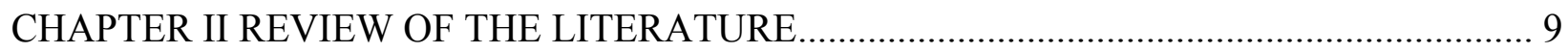

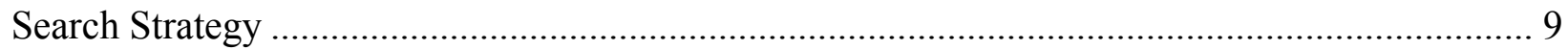

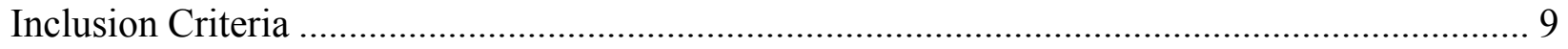

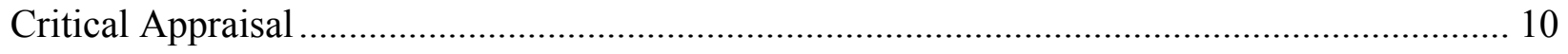

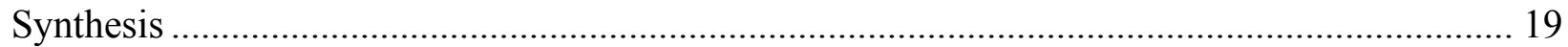

Congruence of Organizations Strategic Plan to the Capstone Project.......................................... 20

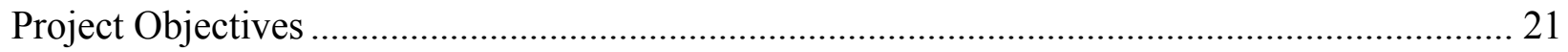

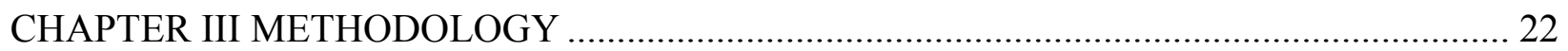

Evidence Based Project/Intervention Plan ...................................................................... 22

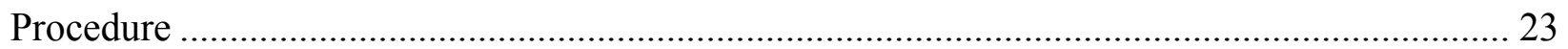

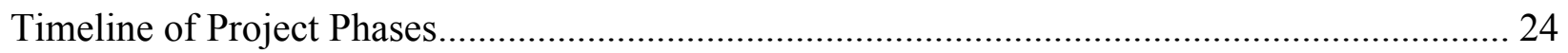

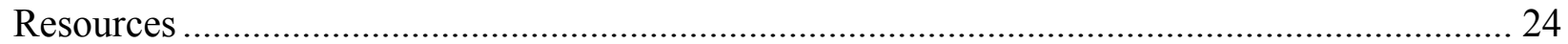

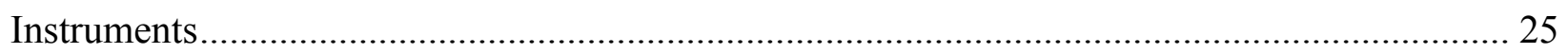

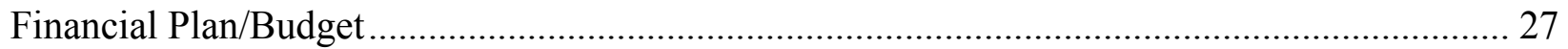

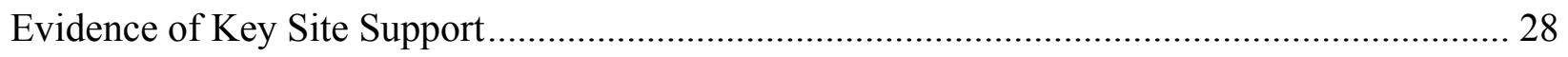

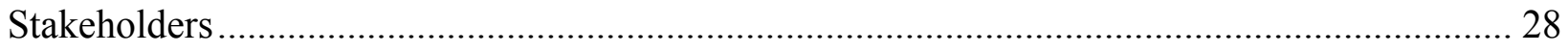




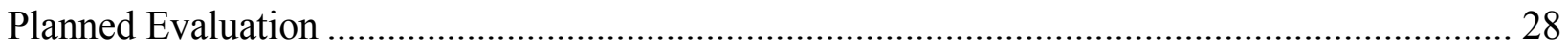

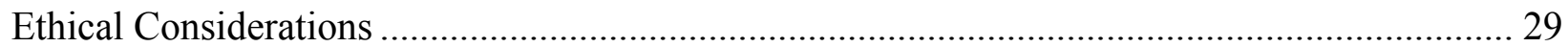

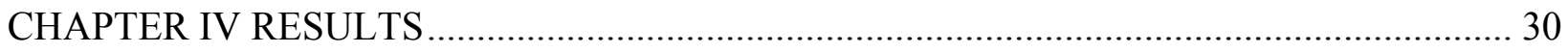

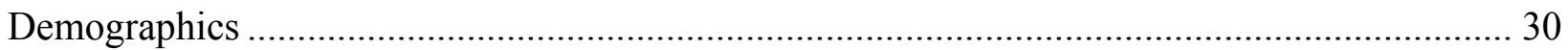

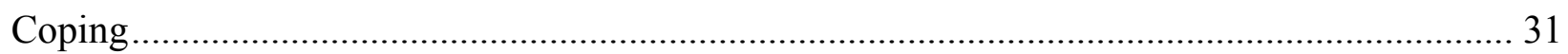

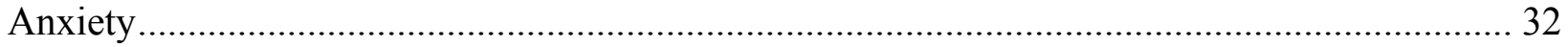

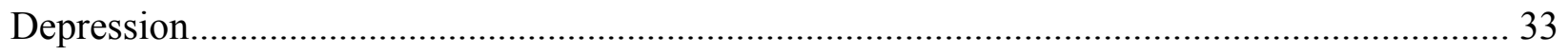

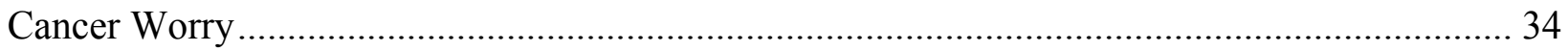

CHAPTER V SUMMARY, DISCUSSION, AND IMPLICATIONS .................................... 35

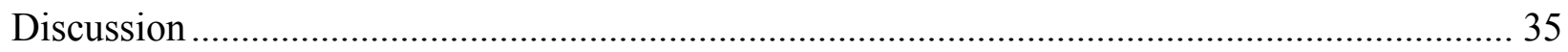

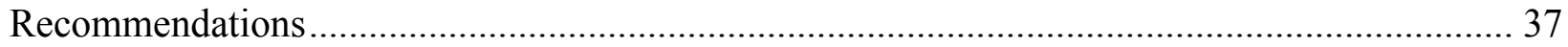

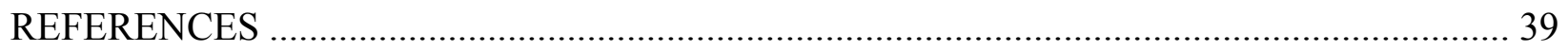

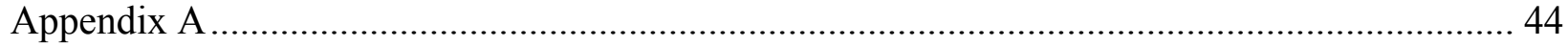

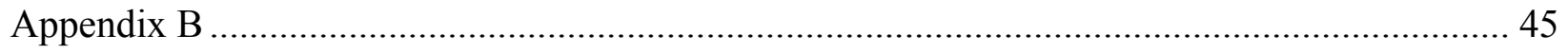

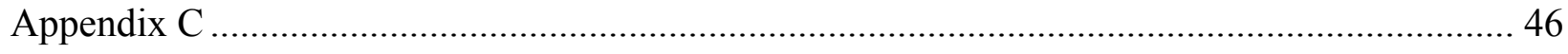

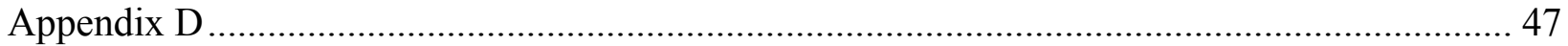

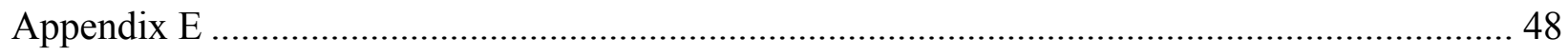

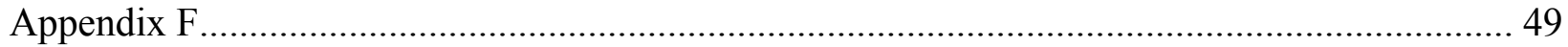

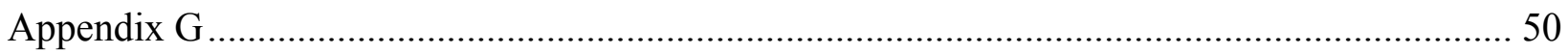




\section{Chapter I}

\section{Introduction}

\section{Background and Significance}

Breast cancer is a major problem worldwide (American Cancer Society [ACS], 2009). It is the most common cancer in women (excluding skin cancer) in the United States and is the second leading cause of cancer death in women (ACS, 2009). It is the leading cause of death in women 35 to 50 (ACS). According to the American Cancer Society (ACS), about 1.3 million women will be diagnosed with breast cancer worldwide and about 465,000 will die from the disease annually. In 2009 there will be approximately 192,370 new cases of invasive breast cancer and 40,170 deaths from breast cancer in the United States. A woman's risk for breast cancer to age 39 is 1 in 210, while women 40 to 59 have a 1 in 26 chance of developing breast cancer. In West Virginia alone, there were over 1,100 new cases of breast cancer in 2008 (ACS, 2009). The site where this capstone project took place, the Edwards Comprehensive Cancer Center (ECCC), is located in Huntington, West Virginia. It is a stand-alone cancer center that is affiliated with Marshall University and Cabell Huntington Hospital. In 2008, 864 cases of cancer were seen at this cancer center with breast cancer the second most commonly treated cancer at $12.7 \% ; 21$ of these cases were women under the age of 50 (ECCC, 2008).

According to the ACS (2009), there are numerous risk factors for breast cancer. Some can be altered, such as the use of hormone replacement therapy, alcohol use, and obesity, but some risk factors cannot be changed. Some of these risk factors include: gender, age, genetics, family and personal history of cancer, race and ethnicity, breast tissue density, menstruation history, history of chest radiation, diethylstilbestrol (DES) exposure, and certain breast 
conditions such as atypical ductal hyperplasia (ADH) and lobular carcinoma in situ (LCIS). Being female is the number one risk factor, mostly because of the exposure to the hormones estrogen and progesterone. The risk for breast cancer increases with increasing age, with $66 \%$ of breast cancers occurring in women over the age of 55. Women who have one first degree relative with breast cancer have twice the risk as the average woman, while having two first-degree relatives with breast cancer increases risk by a factor of five. Approximately 5\%-10\% of breast cancers are hereditary, resulting from an inherited gene mutation. For women who have a genetic mutation, their risk for breast cancer can be as high as $85 \%$ (ACS, 2009).

With screening modalities such as mammography, magnetic resonance imaging (MRI), and clinical breast exams, cancer may be detected in early stages, which has been shown to reduce mortality in breast cancer (Baltzell \& Wrensch, 2005). Mammography should be started at age 40 in women who are at average risk for breast cancer; however, there are some women who are at increased risk for breast cancer who should start screening at an earlier age (ACS, 2009).

Many women have risk factors that can increase their risk for developing breast cancer and they can benefit from personalized recommendations based on their personal and family history. These women may meet criteria for additional pharmacologic or surgical options that can reduce their risk for breast cancer. These options are often not explored at a routine doctor's visit, not just because of a knowledge deficit on the part of the provider but also because of time constraints (Vogel, 2003). Women at high risk may have anxiety or depression based on their family history of breast cancer. Clinics that evaluate familial cancer risk have become much more common, and $80 \%$ of the referrals are women with a family history of breast cancer (Heimdal, Maelhle, \& Miller, 1999). The cost effectiveness of these clinics has not been 
established, however, early studies have found that clinics that promote early detection contribute to the overall psychosocial wellness and health of the patient (Heimdal, et al., 1999). Women who are at increased risk for breast cancer may experience higher levels of anxiety, depression, or cancer worry than women who are at average or slightly increased risk (Lindberg \& Wellisch, 2001). In a study by Meiser et al. (2000), researchers found that both state anxiety and breast cancer related anxiety were associated with an overestimation of personal breast cancer risk. By providing these women with an accurate risk assessment, their anxiety may be decreased, and by extension, cancer worry and depression may decrease (Meiser et al., 2000). This can be done by using objective assessment and discussing screening options. In addition, there are women who are at high risk for breast cancer, such as those who carry a genetic mutation on their breast cancer (BRCA) genes. Since these women may have up to an $85 \%$ lifetime risk for breast cancer and a $27 \%-44 \%$ risk for ovarian cancer, they are unlikely to overestimate their risk. According to a study by Brain et al. (2002), risk assessment in high-risk women only confirms their belief in their risk. Although they do have decreased generalized anxiety, they still have persistent anxiety about breast cancer, which can compromise their quality of life.

A position in a cancer risk assessment clinic is ideal for an advanced practice nurse with specialized training in oncology and risk evaluation. A nurse practitioner can perform risk assessment using validated models, complete a history and physical, make recommendations based on findings for surveillance and interventions, and educate the patient regarding her risk (Vogel, 2003). A study by MacDonald, Sarna, Uman, Grant, and Weitzel (2006) found that almost a third of women at increased risk for breast or ovarian cancer did not receive adequate breast cancer screening prior to attending their risk assessment appointment, while $12 \%$ had 
needless ovarian cancer screening. Twelve percent of the women used untested and potentially harmful "prevention" measures, such as homeopathy or herbs. It was also noted that most of these women did not use chemoprevention or surgical interventions to decrease their risk, although the reasons for not doing so were unclear (MacDonald et al., 2006). Women with a BRCA mutation also have additional considerations such as prophylactic surgery, chemoprevention, screening MRI, and fertility issues.

As breast cancer awareness and the science of genetics have advanced, cancer risk assessment has become an option for women at risk for breast cancer. According to the National Comprehensive Cancer Network (NCCN) Clinical Practice Guidelines: Breast Cancer Risk Reduction (2011), women who are at increased risk for breast cancer should be referred for risk reduction counseling. Individualized risk assessment is becoming increasingly important as more screening and prevention strategies become available. There are multiple models that assess risk, such as the Gail Model (Gail et al., 1989), the Claus Model (Claus, Risch, \& Thompson, 1994), and BRCAPRO (Parmigiani, Berry, \& Aguilar, 1998), and each of these models uses different criteria to assess risk. It is imperative that the practitioner be aware of the strengths and limitations of each of the models, and also be aware that none of the models assesses risk with great accuracy, with the exception of genetic testing. This is because these are mathematical models which calculate risk over a period of time, hence the factors included in the models only account for a small percentage of eventual breast cancer development (Baltzell \& Wrensch, 2005). It is important that women who attend a high-risk clinic feel confident in their personal risk assessment, as major lifestyle decisions may be based on the results. It is also essential that these high risk women see a practitioner that is aware of specialized screening, pharmacologic, and surgical recommendations for these women about which general practitioners may not be 
familiar (Baltzell \& Wrensch, 2005). Lindbergh and Wellisch (2001) noted that health care providers play an important role in patients' compliance with screening procedures. Therefore it is important that a provider that is familiar with the increased screening recommendations discuss these options with women at increased risk. Many general practitioners are unaware of these screening recommendations or recommendations regarding genetic test results.

Genetic testing is limited because only $5 \%-10 \%$ of cancer is hereditary. There are ethical, legal and social implications (ELSI) that are associated with genetic testing that may arise. These must be addressed and the patient must understand the implications. These visits can be very time intensive, and many physicians neither want nor have the time to devote to these visits. A risk assessment counseling session at a nurse led, high-risk clinic may help to allay patients' fears and increase their quality of life (Vogel, 2003). The nurse practitioner's role in these clinics is to examine, educate, and facilitate referrals to empower the patient to make decisions (Vogel, 2003). In response to these findings, the purpose of this capstone project is to evaluate the effect of a nurse-run clinic for women at increased risk for breast cancer on anxiety, depression, and cancer worry.

\section{Theoretical Framework}

The Transactional Model of Stress and Coping (TMSC) (Lazarus \& Folkman, 1984) was the theory chosen to guide the project. The TMSC is a framework for assessing how one copes with stress inducing events. This theory takes into account both the characteristics of the person as well as the environmental event and the relationship between the two. If the person evaluates the situation and determines that the event exceeds his/her coping resources, then his/her wellbeing is endangered in the form of psychological stress (Lazarus \& Folkman, 1984). 
In Lazarus and Folkman's TMSC theory (1984), a person must evaluate the potential threat or stressor, which is called the primary appraisal. There are three different categories of primary appraisal: irrelevant, benign-positive, or stressful. An irrelevant environmental encounter does not affect the person in any way, so there is no concern about the outcome of the encounter. A benign-positive encounter is one in which the person assumes the outcome of the encounter will be constructive, enhancing well-being. These encounters, although positive, may still produce anxiety. A stressful encounter can include the belief that a stressor is currently harmful or may cause a threat in the future. Lazarus and Folkman (1984) theorize that there are three types of stress appraisals, harm/loss, threat, and challenge. These three appraisals are not mutually exclusive; a stressful event can have elements of all three types.

The secondary appraisal is the person's evaluation of his/her coping resources and the controllability of the stressor. The secondary appraisal is the assessment of what can be done to manage the situation. It is an intricate process whereby a person assesses his/her coping resources, evaluates whether he/she believes these resources will work, and whether or not he/she can apply these resources in order to combat the stressor. A person's evaluation of primary and secondary appraisals is complex and determines the reaction to the stressor.

Coping efforts that are employed to control the situation lead to outcomes of coping (Lazarus \& Folkman, 1984). Coping efforts can be negative or positive strategies and mediate the primary and secondary appraisals. These coping efforts may be problem management efforts which attempt to change the stressful situation or emotional regulation which attempts to change how one feels about the stressor. Problem management strategies can include information seeking or problem solving and work best for stressors that can be changed. Emotional regulation can include: denial, avoidance, wishful thinking, self-blame, or social support, and 
work best for stressors that cannot be changed, or when problem management strategies don't work. Other coping efforts can include disengaging strategies, where the person transfers attention away from the stressor, and engaging strategies, where the person sees the stressor as something he/she can control. Meaning-based coping encourages positive feelings and can involve religion or spirituality (Lazarus \& Folkman, 1984).

A person's coping style is the way he/she reacts to a stressor, and is generally relatively stable over time, as opposed to coping efforts, which are the strategies employed to deal with the stressor. Two common types of coping styles are optimism and information seeking. Optimism is the propensity to have a positive outlook. People who are optimistic have been shown to be better adjusted psychologically. People who have information seeking coping style can be vigilant, which is considered monitoring, or avoiders, which is considered blunting. Both monitoring and blunting can have positive and negative outcomes. Coping outcomes are the result of the person's reaction to the stressor. The three main outcomes are emotional well-being, functional status, and health behaviors, all of which can occur at different times (Lazarus \& Folkman, 1984).

Women who are at increased risk for breast cancer may experience higher levels of anxiety and/or cancer worry than women who are at average or slightly increased risk. This anxiety and cancer worry can cause depression. In a study by Meiser et al. (2000), the researchers found that both state anxiety and breast cancer related anxiety were associated with the overestimation of personal breast cancer risk. This demonstrates the need to use a theory that explores emotional needs of patients.

For women who are at increased risk for breast cancer, the stressful event is their risk. They perform a primary appraisal to ascertain if they are threatened by this risk. If they do not 
perceive this as a risk, then they do not experience significant levels of stress and do not need to employ coping mechanisms. These women also undergo a secondary appraisal to determine if they have the coping skills to deal with this stressor. If they do not have adequate coping mechanisms to deal with this stressor, they may employ poor coping strategies by avoiding the situation, causing negative stress. However, if they feel they are able to cope with this stressor, they may use positive coping methods like information seeking (scheduling an appointment at a high risk clinic) to positively deal with their stress. An understanding of the TMSC and coping mechanisms of different patients will help guide the treatment of high risk patients, allowing the practitioner to tailor the educational component of the session to best suit the patient's needs.

Everyone reacts to stress differently. The utilization of the TMSC theory to guide the capstone project is based on the assumption that women will attend this clinic as a coping strategy. It is hoped that educating patients on their personal risk and screening recommendations will decrease their personal stress. It is expected that by decreasing stress, then anxiety, depression, and cancer worry will also be decreased. 


\section{Chapter II}

\section{Review of the Literature}

\section{Search Strategy}

The search strategy for relevant articles included searching National Guidelines

Clearinghouse, the Cochrane Library, Academic Search Complete, EBSCO host, CINAHL, and PUBMED. No limits were set on the years, language or country, but the search was limited to adults. Using the keyword high-risk breast clinic, the initial search yielded 695 hits. The search was narrowed by searching the key words high, risk, breast, cancer, clinic, and anxiety, which yielded 43 hits, 22 of which were appropriate. The search was done combining the same key words with quality of life in place of anxiety, with 24 hits obtained, 9 of which were appropriate. When satisfaction was substituted for quality of life, 22 hits were obtained, 4 were duplicates and 6 were appropriate. Twelve more articles were found by the use of snowballing. An updated search was done using depression and worry with the other key words. Thirty hits were obtained with depression and eleven with worry; all were duplicates. This was later updated to include up to May 2011 but no additional articles appropriate to this project were found. An updated version of the clinical practice guideline (NCCN, 2011) was added.

\section{Inclusion Criteria}

Abstracts of relevant articles were scanned to identify if the study included high or moderate risk women and if they were seen in a clinic setting. Articles that appeared relevant were obtained. Twenty-six articles were printed for consideration. Of these articles, 16 were excluded because anxiety or cancer worry was not the main outcome evaluated; one article was excluded because of unclear inclusion and exclusion criteria. Nine articles that appeared to contain the highest level of evidence and met criteria were assessed for validity for inclusion in 
this review. A clinical practice guideline (CPG) was also added. The nine research articles and one CPG included in this review were the strongest sources of evidence. Of the nine articles chosen, two were systematic reviews (Sivell, Iredale, Gray, \& Coles, 2007; Thewes, Meiser, Tucker, \& Schnieden, 2003), two were randomized controlled trials (Brain et al., 2002; Torrance et al., 2006), two were cross-sectional designs (Trask et al., 2001; Loescher, 2003), two were descriptive studies (Hopwood et al., 2004; Stacey, DeGrasse, \& Johnston, 2002), and one was a longitudinal study (Lobb et al., 2004).

\section{Critical Appraisal}

The Scottish Intercollegiate Guidelines Network (SIGN, 2008) criteria for validity were used to evaluate the systematic reviews (Sivell et al., 2007; Thewes et al., 2003) and the randomized controlled trials (Brain et al., 2002; Torrance et al., 2006). The cross-sectional studies (Trask et al., 2001; Loescher, 2003), descriptive studies (Hopwood et al., 2004; Stacey et al., 2002), and longitudinal study (Lobb et al., 2004) were assessed for validity using the Quantitative Literature Review Worksheet (Larrabee, 2009). None of the studies had a research question, but the objectives were clearly identified in all studies.

The NCCN clinical practice guideline: Breast Cancer Risk Reduction (2009) was assessed using the Appraisal of Guidelines for Research and Evaluation (AGREE) instrument to evaluate validity (AGREE, 2001). This guideline had numerous strengths. Although there was no specific clinical question, it was clear that the objective of the guideline was to address the care and follow up of patients at high risk for cancer due to numerous causes. The development of the guidelines included numerous specialists from many specialties, including oncology and genetics, and the panels often included patient representatives. These guidelines were developed by explicit review of the evidence by recognized experts, and treatment recommendations were 
developed through performance measurement. The methods used to formulate recommendations were clearly described in the guidelines, and the criteria for selecting the evidence was described on their web site. The guidelines clearly delineate who should be referred for risk assessment counseling, and a logarithm guides risk reduction interventions. According to these guidelines, women who have a known or suspected genetic mutation, a close relative with breast and ovarian cancer, a close relative with breast cancer diagnosed prior to age 50 or bilateral breast cancer, a close relative with a combination of breast cancer with specific other cancers, prior thoracic radiation therapy, a personal history of atypical ductal hyperplasia, a personal history of lobular carcinoma in situ, or a five year breast cancer risk greater than or equal to $1.7 \%$ or lifetime risk greater than $20 \%$ with a life expectancy of greater than or equal to 10 years should be referred for risk reduction counseling. Risk reducing surgeries or medications can be offered; patients declining a more aggressive screening will need to be followed. There were a few limitations of these guidelines. There was no pilot study, no potential organizational barriers were discussed, and the costs of applying the recommendations were not considered (NCCN, 2009). There were no changes to the 2011 guidelines regarding recommendations for referral for risk reduction counseling (NCCN, 2011).

The first systematic review (Sivell et al., 2007) evaluated the impact of genetic risk assessment services on patients who were at risk for familial breast cancer. Data searches were conducted using MEDLINE, EMBASE, CIHAHL, PsychLIT, CENTRAL, DARE, ASSIA, Web of Science, SIGLE, and, LILACS. All languages were included, and the search period was from 1985 to 2005 . Two independent reviewers assessed all studies to determine if inclusion criteria were met. A third person arbiter was utilized for issue resolution. The authors had clear criteria for selecting articles, and inclusion criteria were clearly identified. Three randomized controlled 
trials from five papers were included in this review, with 1251 participants. Differences between the papers were evaluated. A meta-analysis was not performed because of the heterogeneity of the studies. The outcomes of interest in the review were general anxiety, breast cancer worry, perceived risk of breast cancer, and patient satisfaction. According to the review, there is a benefit to cancer genetic risk assessment including reduced distress, increased knowledge of breast cancer and genetics, and improved perceived risk. Patients were generally satisfied with services and overall found the appointment very useful. There was no evidence to suggest the assessment caused psychological harm, however, there was no follow up for longer than nine months. This review included a large sample size, but only three trials were included. The authors did note that cancer genetic services had only been established for about 20 years, so there was limited data (Sivell et al., 2009).

The second systematic review (Thewes et al., 2003) described 17 studies for risk of psychological distress in women with a family history of breast cancer. Data searches were rigorous and included the databases MEDLINE, PsychLIT, and EMBASE which were searched from 1980 to 2003. The key phrases hereditary breast cancer, psychological adjustment, psychological distress, anxiety, and depression were searched individually and in combination. A manual search of specialty journals was also done for the years 1990 to 2003. Studies were included if they were published in a peer reviewed journal in English, if the women had a family history of breast cancer but no personal cancer history, if they addressed sociodemographic, family history or distress, and included psychological and emotional outcomes as primary outcome measures. Several studies found an association between perceived risk of developing breast cancer and distress, anxiety, and depression. Some of these studies found associations with psychological outcomes if risk was overestimated by more than $50 \%$. Two of the studies found 
an association between a parent's death from breast cancer and distress, and two studies found that women who had been caregivers for their mothers with breast cancer had higher distress levels. Study results were inconsistent on several potential risk factors. One study found the number of relatives with breast cancer was associated with distress, while another found no association. Studies found significant associations between psychological distress and past psychiatric history, low perceived control, poor adherence to screening, low social support, low sexual satisfaction, low social desirability, poor understanding of general population risk, and hereditary nature of breast cancer. Strengths of this review included a large number of studies and multiple variables assessed, however, data was not combined because of the heterogeneity of the studies (Thewes et al., 2003).

Two randomized controlled trials (RCT) were evaluated (Brain et al., 2002; Torrance et al., 2006). Blinding was not possible in either study due to the nature of the trials. Treatment and control group demographics were similar enough for comparison. The first RCT (Brain et al., 2002) assessed the psychological impact of risk assessment on women with different risk levels. Participants included 653 women who had a first degree female relative diagnosed with breast cancer before age 50, a first degree female relative with bilateral breast cancer, two or more first degree relatives with breast cancer, or a first and second degree relative with breast cancer. Sampling was consecutive and randomly assigned by computer. A surgical staff saw the control group, while the trial group was seen by a multidisciplinary team who conducted genetic risk assessment and counseling. All of the participants completed baseline anxiety tools prior to counseling. These were the State Trait Anxiety Inventory (Spielberger, 1983) and the Breast Cancer Worry Scale (Lerman et al., 1991). They completed the same scales plus a satisfaction survey, the Satisfaction with Genetic Counseling Questionnaire (Shiloh, Avdor, \& Goodman, 
1990), after their appointment. This study found that beliefs about personal risk can be adjusted by risk assessment. For women who were at high risk for breast cancer, risk assessment confirms their belief that they are at increased risk. These women were less satisfied with their consult, regardless of their study group assignment $(\mathrm{P}<0.001)$. Subjects did have decreased generalized anxiety $(\mathrm{P}<0.001)$, but had consistent worries regarding breast cancer, which affected their quality of life. Lower risk women had decreased anxiety and breast cancer concerns regardless of whether or not they had genetic analysis $(\mathrm{P}<0.001)$. From baseline to follow up there was a significant overall reduction in breast cancer worry $(\mathrm{P}<0.001)$. This trial was strengthened by its large sample size and use of randomization; however, it was an English study, so it may not be generalizable to US women. Also, the control group was seen by a surgical specialist group, who may have more genetic expertise than general practice groups (Brain et al., 2002).

The second trial by Torrance et al. (2006) evaluated two concurrent RCTs at two different sites. Results were comparable for both sites. Sampling was consecutive and patients were randomly assigned by computer. One site had 289 participants, while the other had 297 participants. Inclusion criteria included women over 18 with a family history of breast cancer and with the ability to speak English. Women who had a known BRCA mutation were excluded. The control group was seen by a physician-based service, while the treatment group included an evaluation by genetic nurse counselors. The researchers found that for an initial risk assessment consultation, a visit with the nurse appears to be equivalent to a physician visit. Anxiety was measured with the Spielberger (1983) State-Trait Anxiety Inventory (STAI) and the Hospital Anxiety and Depression Scale (HADS) (Zigmund \& Snaith, 1983), depression was measured by the HADS, and patient satisfaction was measured with a modified version of the Satisfaction with Genetic Counseling Questionnaire (Shiloh et al., 1990). A confidence interval approach was 
used for the statistics since this was an equivalence trial. The outcome differences were calculated and adjusted for differences in baseline scores using multiple linear regressions. Equivalence limits were set at \pm 4 for the STAI and $1 / 3$ baseline standard deviation scores for the HADS. There were small reductions in anxiety in all groups, and patient satisfaction was high in all groups. Anxiety and depression scores were calculated and were consistent with equivalence, meaning the $95 \%$ confidence interval for the difference between the intervention and control group fell completely within the predetermined equivalence limit. The results of this study suggest that for the initial visit of a genetic counseling session, nurses can provide care that is comparable to that of physicians related to satisfaction and psychosocial issues. Strengths of this trial included the large sample size and the use of parallel randomized trials; however, this was also an English trial, thus possibly not generalizable to a U.S. sample. Also, the study end point was when the patient learned her risk status, which could have major impact on her anxiety (Torrance et al., 2006).

The remainder of the studies were evaluated using Larrabee's (2009) Quantitative Literature Review Worksheet (Trask et al., 2001; Loescher, 2003; Hopwood et al., 2004; Lobb, et al., 2005). A study by Trask et al. (2001) used a cross-sectional design with a consecutive sampling method. Participants included 290 women with a family history of breast or ovarian cancer in one or more close relatives, or other risk factors leading to increased risk for breast or ovarian cancer. After initial contact with the clinic, potential participants were sent the Clinic Questionnaire (CQ), which collected demographic information, and the Worry Interface Scale (WIS), both of which were created by the authors. Questionnaires were then evaluated and women who had concerns that could be addressed by the clinic were offered appointments. At the initial appointment and prior to counseling, patients completed the Profile of Mood States 
(POMS) (McNair, Lorr, \& Droppleman, 1971) questionnaire and Medical Outcomes Survey Short Form 36 (SF-36) (Ware, 1993) questionnaire. One month after the initial appointment, participants completed the WIS a second time and returned it by mail. Approximately $2 / 3$ of the women felt that worrying about breast cancer interfered with their functioning, and these women generally felt more distressed with significantly higher levels of confusion $(F[1,91]=8.90$; $\mathrm{p}<0.004)$ and anxiety $(\mathrm{F}[1,81]=6.22 ; \mathrm{p}<0.015)$. This study had a large sample size and used multiple tools to assess cancer specific worry, but causality cannot be determined because of the correlational design. The sample also lacked diversity with $70.7 \%$ of the participants being Caucasian, 1.4\% African American, and less than 1\% coming each from Native American, Hispanic, or Asian races. The remaining 26.5\% were either unknown, not asked, or another race (Trask et al., 2001).

Loescher (2003) assessed cancer worry in women with hereditary risk factors for cancer. This study used a cross-sectional design with a convenience sample. Participants were 200 women over 18 with no personal history of breast cancer who met at least one criterion for hereditary breast cancer risk and were recruited from a mammography facility and cancer prevention center. They completed a Thoughts about Cancer Scale (Loescher, 2001) and demographic questionnaire prior to their appointment. Their perceived risk of cancer was assessed by their answer to the question "My chance of developing cancer during my life is _\%”. This study found that these women sometimes worried about developing breast cancer. Having a breast biopsy was significantly correlated with cancer worry, and women with clinical breast symptoms were more likely to have higher levels of breast cancer worry $\left(X^{2}=12.763\right.$, $\mathrm{df}=6, \mathrm{p}=0.047)$. Although this study had a large sample size, it used a newly developed survey tool, participants lacked diversity and participants were recruited from a mammography facility 
and cancer prevention center, so their anxiety may have been decreased from previous consultations (Loescher, 2003).

A study by Hopwood et al. (2004) assessed psychosocial outcomes of counseling services for familial cancer. This was a descriptive study with a convenience sample of 256 women over the age of 18 with no history of cancer. There were five centers included in this study. Results were comparable for all sites. These centers were randomly selected from groups of centers ranked by different levels of clinical activity. Participants completed questionnaires assessing demographics, risk perception (a protocol specific 14 item scale), mental health (General Health Questionnaire [Goldberg \& Williams, 1988]), and health services use (modified Cancer Worry Scale [Watson et al, 1998; Hopwood et al, 2001]). Patient satisfaction was measured at the follow-up visit, and follow-up questionnaires were mailed at one and 12 months. The researchers found that there were no significant differences in psychological distress between the centers at baseline or either follow-up on psychological distress. There was also no significant difference in cancer specific distress. At all centers there was a reduction in cancer worry scores from baseline to one month and baseline to 12 months in participants who inaccurately estimated their risk in either direction $(\mathrm{P}<0.001)$. Patient satisfaction was high at all centers. Strengths of this study included the large sample size and the fact that it was a multi-center study where centers were chosen randomly. However, each center had a small sample size and there was limited information about inclusion and exclusion criteria for participants (Hopwood et al., 2004).

Another descriptive study addressed the support needs of women who were at high risk for breast cancer (Stacey et al, 2002). This study evaluated 97 consecutively sampled women who had a $1.66 \%$ or greater five-year risk for breast cancer, atypical ductal hyperplasia, lobular carcinoma in situ, or a positive genetic test. A self-report questionnaire was completed prior to 
their first visit and a satisfaction survey was completed post visit. The most common information needs noted were personal risk factors, breast cancer prevention and screening, lifestyle changes, use of hormone replacement therapy, genetic testing, and Tamoxifen use. Women were satisfied with the emotional support they received. Although the sample size was small, it was large enough to detect differences. However, the tool they used was not psychometrically tested, and the sample size was mostly well-educated Caucasian women, which may not be generalizable to all high-risk women (Stacey et al., 2002).

A longitudinal study by Lobb et al. (2004) evaluated the differences in communication skills of individuals and whether this affected outcomes such as anxiety, depression, and satisfaction. This was a multi-center study with 158 consecutively sampled participants who were at high risk and had not had genetic testing or a prior consultation. Participants completed a breast cancer genetics knowledge questionnaire (Lerman et al, 1996), Impact of Events Scale (Horowitz, Wilner, \& Alvarez, 1979; Thewes et al, 2001), and the Hospital Anxiety and Depression Scale (Zigmond \& Snaith, 1983) at two weeks prior to their consult and four weeks after their consult. A modified version of the Satisfaction with Genetic Counseling Scale (Shiloh et al, 1990) was completed after the consultation. Counseling sessions were taped and transcribed. Investigators identified that more women had their expectations met when prophylactic surgeries were discussed (mastectomy: $\mathrm{OR}=7.34,95 \% \mathrm{CI}=1.96-27.57, \mathrm{P}=0.003$; oophorectomy: $\mathrm{OR}=17.72,95 \% \mathrm{CI}=2.07-151.62, \mathrm{P}=0.009)$. Also, discussing genetic testing significantly reduced anxiety $(\mathrm{t}=-2.22, \mathrm{P}=0.03)$ and understanding of results significantly reduced depression $(\mathrm{t}=-1.959, \mathrm{P}=0.052)$. Participants received a consultation summary letter and this significantly reduced anxiety $(\mathrm{OR}=0.38,95 \% \mathrm{CI}=0.177-0.806, \mathrm{P}=0.012)$ and significantly increased risk perception $(\mathrm{OR}=2.61,95 \% \mathrm{CI}=1.139-6.017, \mathrm{P}=0.023)$. Women whose provider 
used more supportive communication were significantly more anxious about breast cancer at the four-week follow up $(\mathrm{OR}=1.66,95 \% \mathrm{CI}=1.25-2.19, \mathrm{P}=0.000)$. The authors theorized that this could be due to emotional concerns that were not acknowledged prior to the visit but a significant association between increased anxiety at baseline and increased anxiety about breast cancer was not found. This was a multi-center study with results comparable for all sites. The sample size was also large. However, non-verbal communication was not observed because audiotapes were used, and the sample tended to have a higher educational level than the general population, thus the results might not be generalizable. This was also an Australian study, which may not be generalizable to a U.S. population (Lobb et al., 2004).

\section{Synthesis}

Evidence found by critically appraising these studies indicates that there is a benefit to specialized risk assessment. However, it is difficult to combine and analyze data because results are heterogeneous and multiple tools were used in different studies. Current guidelines (NCCN, 2011) recommend risk reduction counseling for women at increased risk for breast cancer, and after an extensive literature search and appraisal, all studies had data to suggest that women who attend these clinics had decreased anxiety and increased quality of life. In one study (Brain et al., 2002), women at extremely high risk were less satisfied with their consultation and had persistent worries, which affected their quality of life. It has been theorized that these women may always have anxiety. Women who have a genetic mutation such as BRCA 1 or BRCA2 have often seen many relatives develop breast cancer at a young age, and many of these family members may have died, which can increase anxiety, cancer worry or depression (Brain et al., 2002). 
Four of the studies lacked ethnic diversity in their samples, or participants had higher education levels than the general population (Hopwood et al., 2004; Stacey et al., 2002; Lobb et al., 2005; Trask et al., 2001). This makes generalizations to other populations difficult, however, according to Lobb et al. (2005) these women are more motivated and are more likely to attend high-risk clinics. So although the populations of these studies are not generalizable to the general public, they are generalizable to the average population of this type of clinic.

More research is needed to determine anxiety, depression, and cancer worry levels of women at increased risk for breast cancer, and what factors increase or decrease their stress level. With further research, it can be determined what treatments work best for women at increased risk. There also needs to be an inclusion of more diverse participants. Behavioral processes can vary across ethnic and social groups, and this will need to be addressed in future studies (Trask et al., 2001). The proposed project will address these limitations by evaluating the effect of a nurse-run clinic for women at increased risk for breast cancer on anxiety, depression, and cancer worry.

\section{Congruence of Organizations Strategic Plan to the Capstone Project}

The mission of the facility where the capstone project took place is to meet the lifetime healthcare needs of those patients that the clinic serves, to provide the highest level of service, quality and efficiency, and to advance healthcare through education. The goals of this project were based upon this mission. The primary goal was to improve the quality of life of patients by reducing their anxiety, depression, and cancer worry. The plan was to reduce patient's worry, anxiety, and depression by providing evidence based care, following practice guidelines, and educating the patients on their risk for breast cancer. 


\section{Project Objectives}

For this project, there were four main objectives:

1. To tailor the appointment based upon the responses of the woman to the Ways of Coping Checklist (Folkman, Lazarus, Dunkel-Schetter, DeLongis, \& Gruen, 1986).

2. To decrease symptoms of anxiety in women who were experiencing anxiety.

3. To decrease symptoms of depression in women who were experiencing depression.

4. To decrease symptoms of cancer worry in women who were experiencing cancer worry. 


\section{Chapter III}

\section{Methodology}

\section{Evidence Based Project/Intervention Plan}

This project was designed and was implemented based on evidence based guidelines. The NCCN guidelines (2011) recommend a referral to a cancer genetics professional for risk reduction counseling if a woman meets one or more of the criteria for familial risk assessment. These criteria were listed earlier in this paper. This capstone project was implemented using the TMSC to guide the development and execution of the project. This theory takes into account not only cognitive appraisal, but also emotional issues and motivations related to health threats. According to this theory, women who attend a high-risk clinic are exhibiting not just a health behavior, but also a mechanism for coping with their stress (Mularczyk, Decruyenaere, Denayer, \& Evers-Kiebooms, 2007). Also, a patient's coping mechanisms and reaction to stressors directly influences specific health outcomes, such as performing self-breast exam or keeping appointments for office visits or mammography. These acts are not preventative actions, but contribute to early detection, which can cause increased anxiety based on the fear of the findings. By learning the coping styles of patients, different educational interventions can be employed to decrease anxiety, depression, and cancer worry (Barron, Houfek, \& Foxall, 1997).

The goal of this project was to reduce anxiety, depression, and cancer worry in women at increased risk for breast cancer through attendance at a nurse-run clinic. The plan involved measuring these behaviors prior to being seen at the high-risk clinic. The patients underwent a risk reduction analysis session with a nurse practitioner who has had training in risk assessment counseling and hereditary cancer syndromes. Coping methods were assessed, and sessions were tailored based on the results of the questionnaires. The nurse practitioner followed up with the 
patient two weeks after the initial session to answer any further questions and requested that the patient complete the same surveys. The tools that were used included the Brief Zung Self-Rating Depression Scale (Dugan et al., 1998), the State portion of the State Trait Anxiety Inventory (Spielberger, 1983), Lerman's Cancer Worry Scale (Lerman et al., 1991), and a modified version of the Ways of Coping Questionnaire (Folkman et al., 1986). Psychometric data on these scales is included later in this paper. It was anticipated that this project would take approximately three to six months, and enrollment began in January 2011 and was completed in June 2011.

\section{Procedure}

New patient referrals were reviewed by the nurse practitioner for appropriateness and were scheduled for an initial visit. Other patients already had appointments because the physician had seen them in the past. Patients included in this study were new to the nurse practitioner. After the patient was placed in the room by staff, the nurse practitioner discussed this study with the patient and obtained consent if the patient was interested in enrolling. They completed the initial forms at that time. After completion of the forms, the nurse practitioner performed the personalized risk assessment. Their risk reduction options were discussed as appropriate. A referral to psychiatric services was initiated if deemed appropriate by the nurse practitioner and physician. These services were available through the cancer center where the study was taking place. Approximately two weeks after the visit, the nurse practitioner made a follow up phone call to the patient to see if she had any additional questions or concerns and asked her to complete the questionnaires that were completed at the initial visit (with the exception of the Ways of Coping Questionnaire). These forms were mailed to the patient with return envelopes with postage included. At the completion of the study, a $\$ 5$ gift card was mailed to the participants. Thirty patients were enrolled. 


\section{Timeline of Project Phases}

The timeline for this project included three phases:

Phase one started with the development of the high-risk clinic and concluded when institutional review board (IRB) approval was obtained. Tasks that were included in phase one included: (a) establishing office staff and nursing support, (b) establishing administrative and internal physician support (c) establishing external physician support (d) finding necessary tools (e) updating literature search (f) ordering educational materials (g) preparing project for Capstone Committee approval, and (h) preparing project for IRB approval and submission. This phase was completed with IRB approval on January 10, 2011.

Phase two began after IRB approval and involved implementation of the capstone project. Tasks that were included in phase two included: (a) high risk visit, which included consent for enrollment and initial completion of tools, (b) follow up phone call and request for

test completion post visit. This phase was completed on July 1, 2011, which allowed a minimum of two weeks for post-visit surveys to be returned.

Phase three was the evaluation phase and included: (a) analysis of the data obtained during the capstone project (b) evaluation of the project to determine if a practice change is necessary in the high risk clinic, and (c) dissemination of the results. This phase is currently ongoing and will complete with the dissemination of the results of the project.

\section{Resources}

This capstone project required limited resources and many of the necessary supplies that were needed were supplied by the capstone site. The most important resource that was needed was support. The nurse practitioner was able to enroll 30 patients which was the goal for this project by securing administrative and internal physician support for the project. Support from 
external physicians was limited and a strategic plan to increase outside referrals is being considered. External physicians were sent an introductory letter regarding this clinic, and the nurse practitioner and director of the breast center set up face-to-face meetings with key physicians to generate support.

\section{Instruments}

The tools included: the State portion of the State Trait Anxiety Inventory (STAI) (Spielberger, 1983), the Brief Zung Self-Rating Depression Scale (Dugan et al., 1998), and Lerman's Breast Cancer Worry Scale (Lerman et al., 1991). A modified version of the revised Ways of Coping (Folkman et al., 1986) was used to assess the coping process. The STAI Form Y (Appendix A) is a commonly used tool to measure anxiety in adults. It distinguishes between temporary "state" anxiety, which occurs with stressful situations and resolves, and generalized or long-term "trait" anxiety, which is personality traits and are developed in childhood. These two types of anxiety are generally linked; usually individuals with higher trait anxiety will exhibit higher state anxiety when faced with stressful situations (Spielberger, 1983). The STAI is a 40item instrument that utilizes a 4-point Likert scale. Statements evaluate how a person feels at that particular moment, such as "I feel at ease" and "I feel upset", as well as statements that assess how the respondent feels in general, such as "I wish I could be as happy as others seem to be" and "I am a steady person". The STAI has good concurrent validity (up to $\mathrm{r}=0.80$ ) and reliability $(\mathrm{r}=0.77)$, as well as high internal consistency for both state anxiety $(0.89)$ and trait anxiety $(0.91)$, which was replicated in a study of anxiety and compliance in women at high risk for breast cancer (Lindberg \& Wellisch, 2001). For this particular project, only state anxiety was measured since how the respondent felt at the high-risk visit and two weeks after the visit were the outcomes of interest. 
The BZSDS (Appendix B) measured the frequency of self-reported depression symptoms. This tool is an 11-item instrument that was developed by Dugan et al. (1998) from the Zung Self-Rating Depression Scale (ZSDS) (Zung, 1965). Nine questions regarding somatic symptoms are excluded on the BZSDS that are included in the ZSDS. Some of the questions include: "I feel downhearted, blue, and sad" and "I feel hopeful about the future". The feasibility, utility, and reliability of the ZSDS were studied in ambulatory cancer patients (Dugan et al., 1998). Twenty-five oncology clinics enrolled 1109 patients. The alpha coefficients for both scales indicated high levels of internal consistency (ZSDS: 0.84; BZSDS: 0.84). The ZSDS and BZSDS were highly correlated $(\mathrm{r}=0.92)$ and the prevalence of depression symptoms was $35.9 \%$ for the ZSDS and 31.1\% for the BZSDS (Dugan et al., 1998).

The Lerman Breast Cancer Worry Scale (Lerman et al., 1991) consists of three questions (Appendix C): "How worried are you about getting breast cancer someday?" "How much does your worry affect your mood?" and "How much does your worry affect your ability to perform your daily activities?" The patient chooses from: not at all, rarely, sometimes, often, and almost all the time and these choices are assigned a number value. The second and third question are combined as worry impact, and have been found to be highly correlated $(\mathrm{r}=0.63)$. The first question is considered a worry frequency variable but was also highly correlated with the other two questions $(\mathrm{r}=0.64$ and $\mathrm{r}=0.45)$ (Lerman, 1991). The tool also has high internal consistency (Cronbach's alpha=0.86) (Brain et al., 2002).

The Ways of Coping Questionnaire (Folkman et al., 1986) (Appendix D) is a 66-item survey that has been widely used to measure coping. There is a more recent modified version from 1988, but the 1985 version is in the public domain and does not require permission to use. Only minor modifications were made to the 1988 version. Participants indicate the extent to 
which they use different coping skills in response to a specific stressful situation. A 4-point Likert style format is utilized, and the patient chooses from: not used, used somewhat, used quite a bit, and used a great deal. Answers correlate to eight different coping scales, including: confrontive coping, distancing, self-controlling, seeking social support, accepting responsibility, escape-avoidance, painful problem solving, and positive reappraisal. Factor analysis was derived from a study of 75 married couples who were interviewed monthly over five months. They were asked to describe the most stressful situation they had encountered in the previous week, and then complete the questionnaire based on that experience. Items were analyzed using alpha and principal factoring. Thirty-seven items were reliable across all three analyses and loaded high consistently (Folkman et al., 1986). Because this questionnaire was not the only form that needed to be completed for this protocol, it was modified to reduce participant burden. Items were chosen based on appropriateness to this population and high factor loadings. The high-risk visit was modified based on participants' responses to questions. For example, if a woman feels she copes best by seeking social support, then she may benefit from attending a support group meeting. If she copes by escape-avoidance, then it is important to emphasize the importance of early detection and screening. Questions included can be seen in Appendix D. The Zung and Ways of Coping tools are available free of charge and permission to use the Lerman Scale has been obtained from Caryn Lerman by e-mail correspondence (Appendix E). Permission to use the STAI was obtained from Mind Garden (Appendix F). The investigator calculated the reliability of the tools with the sample.

\section{Financial Plan/ Budget}

Educational materials were received from the ACS and National Cancer Institute free of charge. These materials did not directly pertain to the capstone project but are necessary for risk 
assessment education. The institution provided office space, staff, and supplies. The student had access to these resources through her role as the nurse practitioner at the high-risk clinic. The student was responsible for the cost of ordering the STAI as well as the cost of stamps for the return envelopes. Funding was obtained from West Virginia University for a $\$ 5$ gift card to be sent to the patient at the completion of the project.

\section{Evidence of Key Site Support}

Edwards Comprehensive Cancer Center supports numerous internal research projects, and this project had verbal support from the Cancer Center Clinical Director, the Director of the Breast Health Center, and the Director of Research Services. See Appendix G for letters of support.

\section{Stakeholders}

Stakeholders are those who were affected by this project. The key stakeholders for this project were: patients and their family members, administration, staff, and physicians at ECCC, external referring physicians, and the Capstone chair and committee members.

\section{Planned Evaluation}

The objectives of this project were evaluated to determine if it was successful.

Patient responses on the Ways of Coping Checklist (Folkman et al., 1986) were reviewed with the patient as the first objective and incorporated into the educational appointment. Edwards Comprehensive Cancer Center had many resources available to patients, including psychological services and support groups, which were offered to participants free of charge.

The second objective, that women experiencing anxiety prior to the appointment would report a decrease in anxiety after an appointment at a high risk clinic was evaluated by 
comparing baseline STAI scores to those at two weeks post visit. A paired t-test was used to determine statistical significance with a $\mathrm{p}$ value of 0.05 .

The third objective, that women experiencing depression prior to the appointment would report a decrease in depression after appointment at the high risk clinic was evaluated by comparing baseline Brief Zung Self Rating Depression Scale scores to those at two weeks post visit. A paired t-test was used to determine statistical significance with a $\mathrm{p}$ value of 0.05 .

The fourth objective that women experiencing cancer worry prior to the appointment would report a decrease in cancer worry after an appointment at the high-risk clinic was evaluated by comparing Lerman's Cancer Worry Scale scores to those at one two weeks post visit. A paired t-test was used to determine statistical significance with a $\mathrm{p}$ value of 0.05 .

Tracking referrals through the medical record system assessed internal and external physician support. Demographic information was collected as well.

\section{Ethical Considerations}

This project was approved through the Marshall University Institutional Review Board. Enrollment was discussed with prospective patients with the understanding that participation was voluntary and care would not be affected regardless of decision to enroll. Consent was thoroughly discussed and time for questions was allowed. 


\section{Chapter IV}

\section{Results}

\section{Demographics}

All patients seen in the high-risk clinic were offered enrollment in this trial if they met enrollment criteria, and they had not seen the nurse practitioner in the past. Thirty-seven women were offered enrollment in the trial and 30 accepted. All women who met inclusion criteria were offered enrollment. All participants completed the pre-test surveys and twenty-three participants completed the post-visit surveys (76.7\%). Eleven patients were new to the nurse practitioner and had not been seen by the physician in the past. Six of these patients returned their post-visit surveys. Nineteen patients were new to the nurse practitioner but had seen the physician in the past; 17 of these patients returned their post-visit surveys. The sample $(\mathrm{N}=23)$ was $100 \%$ female and 100\% Caucasian. Patient visits were coded as: 1) new patient genetic visit (N=4, 17.4\%), 2) new patient high-risk visit $(\mathrm{N}=2,8.7 \%), 3)$ genetic visit/ has seen Dr. McKinney in past $(\mathrm{N}=5$, $21.7 \%)$, 4) high risk visit/ has seen Dr. McKinney in past $(\mathrm{N}=12,52.1 \%)$. Age of participants ranged from 30 to 82 with a mean age of 52.5. All patients were new to the nurse practitioner. Twenty patients had a family history of breast cancer $(86.9 \%)$. Three patients $(13.1 \%)$ reported a family history of both breast and ovarian cancer. Three patients $(13.1 \%)$ had a personal history of atypical ductal hyperplasia in addition to their family history. Family history was generally by patient report with pathology reports obtained for two cases to confirm breast cancer. It is possible that the reports of ovarian family history were either cervical or endometrial cancer as some patients incorrectly assume a "female" cancer is an ovarian cancer. 


\section{Coping}

The first objective, to tailor the appointment based upon the responses of the woman to the Ways of Coping Checklist was achieved. The revised Ways of Coping Questionnaire was administered and the visit was tailored based on responses. The Ways of Coping Scale has eight coping scales including (see Appendix D for questions): confrontive coping (\#8), distancing (\#3, $\# 13$, \#16), self-controlling (\#4, \#15,\#17), seeking social support (\#2, \#5, \#10,\#14), accepting responsibility (0), escape/avoidance (\#11,\#18,\#19), painful problem solving (\#1,\#7), and positive reappraisal (\#6, \#9, \#12,\#20). As patients can use more than one style of coping, the responses were not mutually exclusive. Confrontive coping occurs when the patient takes aggressive measures to change the situation, and can involve risk taking. If a patient used this kind of coping, it was important to stress the importance of screening, and make sure they understand the risks and limitations of screening and risk reduction modalities. If a patient employed distancing as a coping mechanism, their personal risk and risk factors as well as the importance of screening was stressed, as people who cope in this way may try to diminish their risk. For those patients that used self-controlling as a coping mechanism, it was important to provide written educational materials as they may not immediately ask questions and internalize their feelings. Seeking social support was another coping method, and it involved seeking tangible support, whether from friends or professionals. Simply coming to the appointment fulfilled this method, and written and verbal educational information was given. Information was also given regarding the support group for breast cancer. Accepting responsibility involved taking personal responsibility for the problem. No questions were included in the modified scale as it was not appropriate for the purpose of the study. Escape or avoidance included trying to forget or avoid the problem, and in cases where a patient employed this, it was necessary to 
determine what techniques she used to avoid the problem. For example, if she smoked, smoking cessation options were discussed. Planful problem solving is an analytical method of approaching problem solving. In patients who used this mechanism, a written plan was given and discussed. Positive reappraisal focuses on personal growth and may have a religious aspect. Information on the facility's counseling services and support group were given to these patients. It is important to recognize that all patients cope differently and most people use a combination of many of these coping skills, not just one particular type. Therefore, all patients were provided verbal information and were offered written materials. Their personalized screening schedule or risk assessment was also available in a paper format. The support group and counseling services were available to all patients.

Using descriptive statistics, there were four responses in which the majority of participants marked as "used a great deal". These included: "I made a plan of action and followed it", "Talked to someone who could do something concrete about the problem", "Rediscovered what is important in life", and "I prayed".

\section{Anxiety}

The second objective, to decrease anxiety in women who were experiencing anxiety, had marginally significant results. The state portion of the State Trait Anxiety Inventory was administered prior to the educational session and was mailed again approximately two weeks after the visit. The mean of the total scores $(\mathrm{N}=23)$ at pre-visit was 38.48 and post-visit was 35.30. Sixteen of the patients who returned their surveys $(69.6 \%)$ had anxiety scores that decreased after their visit. Using a paired t-test, results were significant at $\mathrm{p}=0.047$ (95\% CI; 0.047-6.308). Six patients (26\%) received a score on their pre-test, which indicated they may be 
anxious. Three of these patients were on medications for anxiety from another provider prior to the high-risk visit. All of the patients were offered a counseling visit.

Cronbach's alpha was performed to assess reliability of this tool. Because questions are asked in both positive and negative formats, it was necessary to reverse the scores of 10 of the items. The alpha coefficient score was 0.957 , indicating good reliability of this tool with this sample.

\section{Depression}

The third objective, to decrease depression in patients that are experiencing depression was not significant. The Brief Zung Self Rating Depression Scale was also administered to participants prior to the educational session and was mailed again approximately two weeks after the visit. The mean of the total scores $(\mathrm{N}=23)$ at pre-visit was 22.13 and post-visit was 21.13. Thirteen of the patients who returned their surveys had a decrease in depression scores (56.5\%); one patient had the same score $(0.04 \%)$. Using a paired t-test, results were not significant at $p=0.252(95 \% \mathrm{CI} ;-0.764-2.764)$. Six patients (26\%) received a score on their pre-test, which indicated they were moderately depressed. Three of these patients were on medications for depression from another provider prior to the high-risk visit. All of the patients were offered a counseling visit.

Cronbach's alpha was again performed to assess reliability of this tool. Because questions are asked in both positive and negative formats, it was necessary to reverse the scores of 3 of the items. The alpha coefficient score was 0.896 , indicating good reliability of this tool with this sample. 


\section{Cancer Worry}

The Lerman's Breast Cancer Worry Scale was administered prior to the educational session and was mailed again approximately two weeks after the visit. The mean of the total scores $(\mathrm{N}=23)$ at pre-visit was 7.00 and post-visit was 6.96. Eleven of the patients who returned their surveys had a decrease in cancer worry scores (47.8\%); four patients had the same score (17.4\%). Using a paired t-test, results were not significant at $\mathrm{p}=0.909(95 \% \mathrm{CI} ;-0.733-0.820)$. Cronbach's alpha was performed on the three questions and was 0.882 , indicating good reliability of the tool with this sample. 


\section{Chapter V}

\section{Discussion and Recommendations}

\section{Discussion}

The purpose of this project was to evaluate if anxiety, depression, and/or cancer worry was decreased in women at increased risk for breast cancer who had any or all of these symptoms after a visit at a high risk clinic. Their coping mechanisms were evaluated prior to the visit as well, and the visit was tailored to best meet their educational needs.

Coping involves dealing with stressful situations, and everyone has different ways of dealing with stress. In this sample, two of the most used coping mechanisms on the coping scale involved gathering more information. A visit at a high-risk clinic involves personalized information on a patient's risk of cancer as well as education on specific conditions of the breast, including atypical ductal hyperplasia, lobular carcinoma in situ, or family history of breast cancer. By gathering data the patient may be better able to cope with her risk for cancer. It is hoped that by educating the patient on their risk as well as early detection methods that any anxiety, depression, and/or cancer worry they may have will be decreased.

There were six patients who were offered a referral to a mental health professional based on their results on the STAI (greater than 55). Three of these patients returned their post-visit surveys and all three STAI scores decreased. If patients had a score of 33 or above on the BZSDS, they were offered a consultation with our psychiatric services. The BZSDS categorizes scores into normal (11-21), mild (22-32), moderate (33-38), or severe (39-44) ranges for depression. The same six patients who had increased anxiety scores also scored 33 or above (34 was the highest score) on the pre-survey and no patients scored 33 or above on the post. However, only three returned their post-visit surveys. 
Six patients were offered referrals to a mental health professional based on their STAI and BZSDS scores. Five patients declined a visit with the psychologist; two of these were already under the care of mental health professionals. One agreed to the visit, but never returned calls to the psychologist. It is possible that at least some of these patients that had anxiety and/or depression unrelated to their risk for cancer, especially the two that were already under the care of a mental health specialist. It is very difficult to ascertain if the anxiety and/or depression is due to risk for cancer or other factors.

Although mean anxiety and depression scores decreased, the decrease was significant only for anxiety. The cancer worry scale scores only had a very slight decrease in means and were not significant. There may be a few reasons for this. First, over half of the patients enrolled had seen a fellowship trained breast surgeon at a previous visit. Their personal risk and screening recommendations had likely been discussed at prior visits, which may have decreased their anxiety, depression, and/or cancer worry, which has been the case in other studies (Loescher, 2003; Brain et al., 2002). There were 11 patients that were completely new to the nurse practitioner, but of these 11 , only five completed the post-visit surveys, so the sample size was too small to produce meaningful results. Secondly, although both the STAI and BZSDS are well validated in the oncology setting, there is limited information on the use of these tools in women who are at increased risk for breast cancer but unaffected with the disease itself. More research is needed in high-risk clinics and hereditary assessment in the oncology realm to identify tools that are appropriate in this setting.

There were a few limitations to this study. The main limitation is the small sample size. All patients who met criteria were offered enrollment and only seven patients declined. There were few new referrals to the high-risk clinic and the reasons for this are going to be explored 
further at the ECCC. The majority of the patients seen for genetic counseling had a personal history of cancer, thus were excluded from this study. Given a longer time period for enrollment, more results might have reached significance. There also may have been more diverse participation if the enrollment period were longer.

A second limitation is that the patients' feelings regarding their personal risk were not recorded. It's possible that the patients enrolled had a realistic view of what their actual risk was, so their anxiety, depression, and/or cancer worry may not have decreased after the visit. Four of the patients had BRCA testing but only two of them completed their post-visit surveys. Neither patient had her results prior to completing the post-visit surveys, which could have affected their results. Two of the patients had known mutations in their family so single site testing was performed and both tested negative, making their results a true negative. Their risk of having the deleterious mutation was $50 \%$, so their anxiety, depression, and/or cancer worry may have been much higher than those whose family histories were not as compelling. However, only one of them completed her surveys and this was prior to receiving results.

A third limitation of this project was the study design. A convenience-sampling format was used, there was no control group, and there was no randomization. By using a different design, rigor may have been increased.

\section{Recommendations}

The NCCN guidelines (2011) recommend risk assessment as well as an increased screening regimen for those who meet criteria. Although results were only significant for anxiety, these measures should still be assessed at clinic visits for women who are at increased risk for breast cancer, even if it is not by formal survey. An action plan is being discussed to increase outside referrals to the high-risk clinic, which would increase the patient pool for further 
research. If further research is conducted, a larger sample size should be considered. The question "My risk of breast cancer is ___ $\%$ " should be asked prior to the visit as well as after the visit so the researcher can determine if the patient has an accurate view of her risk. Different tools to measure anxiety and depression could be considered as well. Women who are BRCA mutation positive are at much higher risk, and this would be an excellent population in which to study anxiety and cancer worry, but this population is very small. A recommendation for a practice change that is being considered is sending a patient a summary letter after their initial visit, outlining their risk and a personalized screening schedule.

In summary, there is a recommendation for possible practice changes at ECCC. Continuing to measure anxiety, depression, and cancer worry should be considered, even if not by formal survey. The patients coping skills and emotional state should be evaluated at each visit and referrals to appropriate ancillary personnel should be made as needed. A summary letter of the patient's personal risk should be sent after the initial visit. Keeping abreast of the literature for new evidence based recommendations should be done intermittently for new research on this topic. 


\section{References}

AGREE collaboration. (2001). Appraisal of guidelines for research \& evaluation (AGREE) instrument. Retrieved October 15, 2009, from www.agreecollaboration.org. American Cancer Society. (2009). Detailed guide: Breast cancer. Retrieved October 25, 2009, from http://www.cancer.org/docroot/CRI/CRI_2_3x.asp?dt=5

Baltzell, K. \& Wrensch, M. (2005). Strengths and limitations of breast cancer risk assessment. Oncology Nursing Forum, 32(3), 605-614. doi: 10.1188/05.ONF.605-616

Barron, C., Houfek, J., \& Foxall, M. (1997). Coping style, health beliefs, and breast selfexamination. Issues in Mental Health Nursing, 18, 331-350.

Brain, K., Norman, P., Gray, J., Rogers, C., Mansel, R., \& Harper, P. (2002). A randomized trial of specialist genetic assessment: psychological impact on women at different levels of familial breast cancer risk. British Journal of Cancer, 86, 233-238. doi:10.1038/sj/bjc/6600051

Claus, E., Risch, N., \& Thompson, W. (1994). Autosomal dominant inheritance of early-onset breast cancer: Implications for risk prediction. Cancer, 73, 643-651.

Dugan, W., McDonald, M., Passik, S., Rosenfeld, B., Theobald, D., \& Edgerton, S. (1998). Use of the Zung self-rating depression scale in cancer patients: Feasibility as a screening tool. Psycho-Oncology, 7, 483-493.

Edwards Comprehensive Cancer Center (2008). Tumor registry data, obtained October 25, 2009 from tumor registrar. 
Folkman, S., Lazaurs, R., Dunkel-Schetter, C., DeLongis, A., \& Gruen, R. (1986). The dynamics of a stressful encounter: Cognitive appraisal, coping, and encounter outcomes. Journal of Personality and Social Psychology, 50, 992-1003.

Gail, M., Brinton, L., Byar, D., Corle, D., Green, S., Shairer, C., \& Mulvihill, J. (1989). Projecting individualized probabilities of developing breast cancer for white females who are being examined annually. Journal of the National Cancer Institute, 81(24), 1879-86.

Goldberg D, Williams P (1988). A User's Guide to the General Health Questionnaire. Windsor: NFER-NELSON Publishing Co Ltd

Heimdal, K., Maelhle, L., \& Moller, P. (1999). Costs and benefits of diagnosing familial breast cancer. Disease Markers, 15, 167-173.

Hopwood, P., Wonderling, D., Watson, M., Cull, A., Douglas, F., Cole, T., ... McPherson, K. (2004). A randomized comparison of UK genetic risk counseling services for familial cancer: Psychosocial outcomes. British Journal of Cancer, 91, 884-892. doi:10.1038/sj.bjc.6602081

Hopwood, P., Shenton, A., Fletcher, I., Lalloo, F., Evans, G., \& Howell, A. (2001). Risk perception and cancer worry: an exploratory study of the impact of genetic risk counseling in women with a family history of breast cancer. J Med Genet 38, 139-142.

Horowitz, M., Wilner, N., \& Alvarez, W. (1979). Impact of event scale: a measure of subjective stress. Psychol Med 41, 209-218.

Larrabee, J. (2009). Nurse to nurse: evidence-based practice. New York: McGraw Hill Medical.

Lazarus, R., \& Folkman, S. (1984). Stress, appraisal, and coping. New York, NY: Springer Publishing Company, Inc. 
Lerman, C., Narod, S., Schulman, K., Hughes, C., Gomez-Caminero, A., Boney, G.,...Lynch, H. (1996). BRCA1 testing in families with hereditary breast-ovarian cancer: A prospective study of patient decision making outcomes. JAMA, 275, 1885-1892.

Lerman, C., Trock, B., Rimer, B., Jepson, C., Brody, D. \& Boyce, A. (1991). Psychological side effects of breast cancer screening. Health Psychology, 10, 259-267.

Lindberg, N. \& Wellisch, D. (2001). Anxiety and compliance among women at high risk for breast cancer. Annals of Behavioral Medicine, 23(4), 298-303.

Loescher, L. (2003). Cancer worry in women with hereditary risk factors for breast cancer. Oncology Nursing Forum, 30(5), 767-772. doi:10.1188/03.ONF

Lobb, E., Butow, P., Barratt, A., Meiser, B., Gaff, C., Young, M.,...Tucker, K. (2004). Communication and information giving in high risk breast cancer consultations: Influence on patient outcomes. British Journal of Cancer, 90, 321-327. doi: 10.1038/sj.bjc. 6601502

MacDonald, D., Sarna, L., Uman, G., \& Weitzel, J. (2006). Cancer screening and risk-reducing behaviors of women seeking genetic cancer risk assessment for breast and ovarian cancers. Oncology Nursing Forum, 33(2), 27-35. doi:10.1188/06.ONF.E27-E35

McNair, D., Lorr, M., \& Droppleman, L. (1971). EDITS Manual for the Profile of Mood States (POMS). Educational and Industrial Testing Service: San Diego, CA.

Meiser, B., Butow, P., Schnieden, V., Gattas, M., Gaff, C., Harrop, K.,...Tucker, K. (2000). Psychological adjustment of women at increased risk of developing hereditary breast cancer. Psychology, Health, \& Medicine, 5(4), 377-388. doi:10.1080/13548500020002190 
Mularcyzyk, E., Decruyenaere, M., Danayer, L., \& Evers-Kiebooms, G. (2007). A theoretical psychological perspective on predictive testing for late onset hereditary diseases. Genetic Counseling, 18(4), 367-378.

National Comprehensive Cancer Network (2009). Breast cancer: Risk reduction [PDF file]. Available from NCCN Web site, http://www.nccn.org/professionals/physician_gls/PDF/breast_risk.pdf

Parmigiani, G., Berry, D., \& Aguilar, O. (1998). Determining carrier probabilities for breast cancer-susceptibility genes BRCA1 and BRCA2. American Journal of Human Genetics, 62, 145-158.

Scottish Intercollegiate Guidelines Network. (2008). Critical appraisal: Notes and Checklists. Retrieved October 15, 2009, from http://www.sign.ac.uk/methodology/index.html

Shiloh, S., Avdor, O., \& Goodman, R. (1990). Satisfaction with genetic counseling: Dimensions measurement. American Journal of Medical Genetics, 37, 522-529.

Sivell, S., Iredale, R., Gray, J., \& Coles, B. (2007). Cancer genetic risk assessment for individuals at risk of familial breast cancer. Cochrane Database of Systematic Reviews 2007, 2, 1-28.

Spielberger, C. (1983). Manual of the State-Trait Anxiety Inventory. Palo, CA: Consulting Psychologists Press.

Stacey, D, Degrasse, C., \& Johnston, L. (2002). Addressing the support needs of women at high risk for breast cancer: Evidence-based care by advanced practice nurses. Oncology Nursing Forum, 29(6), E77-E84. doi:10.1188/02.ONF.E77-E84 
Thewes, B., Meiser, B., Tucker, K., \& Schnieden, V. (2003). Screening for psychological distress and vulnerability factors in women at increased risk for breast cancer: A review of the literature. Psychology, Health \& Medicine, 8(3), 289-304. doi: $10.1080 / 1354850031000135731$

Thewes, B., Meiser, B., \& Hickie, I. (2001). Validation of the impact of Events Scale in women at increased risk of developing hereditary breast cancer. Psycho-oncology 10, 459-468.

Torrance, N., Mollison, J., Wordsworth, S., Gray, J., Miedzybrodzka, Z., Haites, N. ,...Wilson, B. (2006). Genetic nurse counselors can be an acceptable and cost-effective alternative to clinical geneticists for breast cancer risk genetic counseling. Evidence from two parallel randomized controlled equivalence trials. British Journal of Cancer, 95, 435444. doi:10.1038/sj.bjc.6603248

Trask, P., Paterson, A., Wang, C., Hayasaka, S., Milliron, K., Blumberg, L., ... Murray, S. (2001). Cancer-specific worry interference in women attending a breast and ovarian cancer risk evaluation program: Impact on emotional distress and health functioning. Psycho-Oncology, 10, 349-360. doi:_10.1002/pon.510

Vogel, W. (2003). The advanced practice nursing role in a high-risk breast cancer clinic. Oncology Nursing Forum, 30(1), 115-122. doi: 10.1188/03.ONF.115-122

Ware, J. (1993). SF-36 Health Survey: Manual and interpretation guide. Health Institute, New England Medical Center: Boston, MA.

Watson, M., Duvivier, V., Wade-Walsh, M., Ashley, S., Davidson, J., Papaikonomou, M.,... Eeles, R. (1998). Family history of breast cancer: what do women understand and recall about their risk? J Med Genet 35, 731-738. 
Zigmond A. \& Snaith R. (1983). The Hospital Anxiety and Depression Scale. Acta Psychiatr Scand, 67, 361-370.

Zung, W. (1965). A self-rating depression score. Archives General Psychiatry, 12, 63-70. 


\section{Appendix A}

Mind Garden allows for the reproduction of five sample items to be included in a proposal (Appendix F).

-I feel calm.

-I feel secure.

-I am tense.

-I feel strained.

-I feel at ease. 


\section{Appendix B}

\section{Zung Self Rating Depression Scale}

Please mark $(\mathrm{X})$ the box that best corresponds to how often you have felt that way during the past week.

\begin{tabular}{|c|c|c|c|c|}
\hline & $\begin{array}{l}\text { None or a } \\
\text { Little of } \\
\text { the Time }\end{array}$ & $\begin{array}{l}\text { Some } \\
\text { of the } \\
\text { Time }\end{array}$ & $\begin{array}{l}\text { Good } \\
\text { Part of } \\
\text { the Time }\end{array}$ & $\begin{array}{l}\text { Most or } \\
\text { All of the } \\
\text { Time }\end{array}$ \\
\hline 1. I feel downhearted, blue, and sad & 1 & 2 & 3 & 4 \\
\hline $\begin{array}{l}\text { 2. I enjoy looking at, talking to, and } \\
\text { being with attractive men/women }\end{array}$ & 4 & 3 & 2 & 1 \\
\hline 3. My mind is as clear as it used to be & 4 & 3 & 2 & \\
\hline $\begin{array}{l}\text { 4. I find it easy to do the things I used to } \\
\text { do }\end{array}$ & 4 & 3 & 2 & 1 \\
\hline 5. I feel hopeful about the future & 4 & 3 & 2 & 1 \\
\hline 6. I am more irritable than usual & 1 & 2 & 3 & 4 \\
\hline 7. I find it easy to make decisions & 4 & 3 & 2 & 1 \\
\hline 8. I feel that I am useful and needed & 4 & 3 & 2 & 1 \\
\hline 9. My life is pretty full & 4 & 3 & 2 & 1 \\
\hline $\begin{array}{l}\text { 10. I feel that others would be better off } \\
\text { if I were dead }\end{array}$ & 1 & 2 & 3 & 4 \\
\hline 11. I still enjoy things I used to & & 3 & & \\
\hline
\end{tabular}




\section{Appendix C}

\section{Lerman's Breast Cancer Worry Scale}

\section{Worry Frequency}

1. How worried are you about getting breast cancer someday?

$1=$ not at all; $2=$ rarely; $3=$ sometimes $; 4=$ often; $5=$ almost all the time

\section{Worry Impact}

2. How much does your worry affect your mood?

$1=$ not at all; $2=$ a little; $3=$ somewhat; $4=$ a lot

3. How much does your worry affect your ability to perform your daily activities?

$1=$ not at all; $2=$ a little; $3=$ somewhat; $4=\mathrm{a}$ lot 


\section{Appendix D}

Ways of Coping Scale (Revised for use in the Capstone Project "An Evaluation of the Effect of a Nurse-Run Clinic for Women at Increased Risk for Breast Cancer on Anxiety, Depression, and Cancer Worry"

1. Just concentrated on what I had to do next- the next step.

2. Talked to someone to find out more about the situation.

3. Went on as if nothing had happened.

4. I tried to keep my feelings to myself.

5. I got professional help.

6. Changed or grew as a person in a good way.

7. I made a plan of action and followed it.

8. I let my feelings out somehow.

9. I came out of the experience better than when I went in.

10. Talked to someone who could do something concrete about the problem.

11. Tried to make myself feel better by eating, drinking, smoking, using drugs or medication, etc.

12. Rediscovered what is important in life.

13. Didn't let it get to me; refused to think too much about it.

14. I asked a relative or friend I respected for advice.

15. Kept others from knowing how bad thing were.

16. Made light of the situation; refused to get too serious about it.

17. I tried to keep my feelings from interfering with things too much.

18. Wished that the situation would go away or somehow be over with.

19. Had fantasies or wishes about how things may turn out.

20. I prayed. 


\title{
Appendix E
}

\section{Permission to use Lerman Scale}

No problem. Good luck

\author{
Caryn Lerman PhD
}

Mary W Calkins Professor

Department of Psychiatry and

\author{
Annenberg School
}

Deputy Director

Abramson Cancer Center

On Mar 28, 2010, at 1:13 PM, "Lisa Muto" < Lisa.Muto@chhi.org> wrote:

\begin{abstract}
Dr. Lerman, I am a WVU Doctor of Nursing Practice student in Huntington, West Virginia at the Edwards Comprehensive Cancer Center. I am a women's health nurse practitioner, and I run our Hereditary Cancer Risk Assessment Program, counseling patients on hereditary cancer syndromes. We have recently started a program for women at increased risk for breast cancer, and I will be seeing women in this clinic. For my capstone project, I will be measuring anxiety and depression in women at increased risk for breast cancer. I would like to determine if their anxiety and depression are decreased and quality of life is increased if they attend a nurse led high-risk clinic. I am planning on using the Zung anxiety and depression scales, and would also like to use your "Breast Cancer Worry Scale" with your permission. Please feel free to contact me with any questions. My e-mail address is lisa.muto@chhi.org and my phone number is (304)399-6572. Thank you for your assistance.
\end{abstract}

Thank you,

Lisa Muto

\section{Appendix F}




\section{mind garden}

\section{www.mindgarden.com}

To whom it may concern,

This letter is to grant permission for the above named person to use the following copyright material;

Instrument: State-Trait Anxiety Inventory for Adults

Authors: Charles D. Spielberger, in collaboration with R.L. Gorsuch, G.A. Jacobs, R. Lushene, and P.R. Vagg

Copyright: 1968, 1977 by Charles $D$. Spielberger

for his/her thesis research.

Five sample items from this instrument may be reproduced for inclusion in a proposal, thesis, or dissertation.

The entire instrument may not be included or reproduced at any time in any other published material.

Sincerely,

Robert Most

Mind Garden, Inc.

www.mindgarden.com

STAIB-AD, @ 1983 Consulting Psychologists Press, Inc. All Rights Reserved.

Published by Mind Garden, Inc., www.mindgarden.com 
Appendix G

Letters of Support 
$1400 \mathrm{Hal}$ Greer Boulevard

Huntington. West Virginia 25701

304.399.6500

September 13, 2010

()lice of Research Integrit!

s8o (hesmut Ridge Rond

P() Box $6.8+5$

Yorgantomn. $11 \mathrm{~V} 2050(16-68.5$

lo Whom It May c 'oncern:

I am writing on behall of lisa Muto, an employec of lidwards ( omprehensive ( anneer

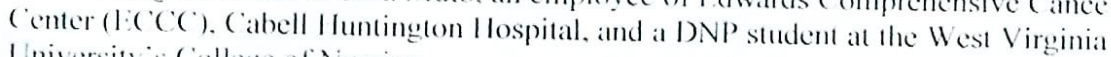
University's college of Nursing.

Lisa is currently working with the I: 'C C rescarch department lior submission of her cxpedited IRB application to West Virginia I miversity, for the study entitled "An fialuation of the lallect of a Nurse-Run ( 'linic for Women at Increased Risk for Breast ('ancer on Anxiely. Depression, and (ancer Worry." All research conducted an l:C ( $C^{\circ}$ and (abell Huntington Ilospital is reviewed by the Marshall University"s IRIS to assure appropriateness of the project for our patient population.

I.isa has the full support of the lac C ' in conducting this project. As Director of ('linical Services at EC C C. I an excited that Lisa has elected to conduct his project here and will be happy to assist in any way. Shawn Mckinney, M.I). F.A.C.S., will serve as I isa's clinical Mentor in this project.

sincerel!.

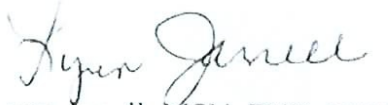

l.ymn ,arrell. MSN. FNP. ()( $\mathrm{NK}$

Director of Clinical Services/Edwards Comprehensive Cancer Center 
$1400 \mathrm{Hal}$ Greer Boulevard

Huntington, West Virginia 25701

304.399.6500

September 8, 2010

Office of Research Integrity

886 Chestnut Ridge Road

P() Box 6845

Morgantown. WV 26506-6845

To Whom It May Concern:

I am writing on behalf of Lisa Muto, a fellow employee of Edwards Comprehensive Cancer Center (ECCC) of Cabell Huntington Hospital in Huntington, West Virginia. Lisa is currently enrolled as a DNP student at the West Virginia University's College of Nursing.

As Director of the Diagnostic Breast Center at ECCC, I have worked closely with Lisa as she has implemented a Breast Cancer Risk Assessment Program under the direction of Shawn McKinney, M.D., F.A.C.S. for identifying women at a higher risk of breast cancer. Lisa is very knowledgeable and compassionate about this much needed program and is making a difference in these women's lives.

As part of her capstone project, Lisa is currently working with the ECCC research department for submission of her expedited IRB application to West Virginia University, for the study entitled "An Evaluation of the Effect of a Nurse-Run Clinic for Women at Increased Risk for Breast Cancer on Anxiety, Depression, and Cancer Worry." Marshall University's IRB reviews all research conducted at ECCC and Cabell Huntington Hospital to assure appropriateness of the project for our patient population.

Lisa has the full support of the ECCC diagnostic breast center in conducting this project. I am excited that Lisa has elected to conduct this project here and will be happy to assist in any way. Shawn McKinney, M.D., F.A.C.S., will serve as Lisa's Clinical Mentor in this project.

Sincerely,

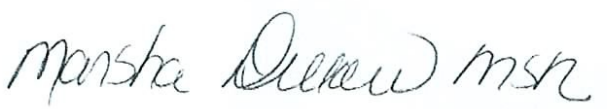

Marsha Dillow, RN MSN

Director of Cabell Huntington Hospital Breast Health Center and

Edwards Comprehensive Cancer Diagnostic Breast Center

An affiliate of Cabell Huntington Hospital and Marshall University Joan C. Edwards School of Medicine 
September 13, 2010

Office of Research Integrity

886 Chestmut Ridge Road

P() BOX 6845

Morgantown. WV 26506-6845

To Whom It May Concern:

I am writing on behalf of Lisa Muto, a fellow employee of Edwards Comprehensive Cancer Center (ECCC), Cabell Huntington Hospital, and a DNP student at the West Virginia University's College of Nursing.

As Clinical Research Supervisor at ECCC, I have worked with closely Lisa on several previous projects and committees. She is currently working with our research department to ensure proper IRB submission of her current study entitled "An Evaluation of the Effect of a Nurse-Run Clinic for Women at Increased Risk for Breast Cancer on Anxiety, Depression, and Cancer Worry." Upon approval of her expedited IRB application to West Virginia University, the study will be sent to Marshall University IRB for local review to assure appropriateness of the project for our patient population. Lisa is enthusiastic and committed to the success of this project.

Oncology Nursing Society has identilied examining the impact of high risk for cancer as one of the Priority Topics for Research 2009 -2013. I am excited that Lisa has elected to conduct this important project here, and will be happy to assist in any way. Lisa has the full support of the ECCC research department in conducting this project. Shawn McKinney, M.D., F.A.C.S., will serve as Lisa’s Clinical Mentor in this project.

Sincerely<smiles>C1C[SiH2]C1</smiles>

$$
\text { Ciro }
$$

Leann Ross, RN, OCN(B), CCRP

Clinical Research Supervisor, Edwards Comprehensive Cancer Center 